\title{
Association of Pain Catastrophizing with Postnatal Depressive States in Nulliparous Parturients: A Prospective Study
}

This article was published in the following Dove Press journal: Neuropsychiatric Disease and Treatment

\author{
Yanzhi Zeng (D' \\ Chin Wen Tan (1D) ${ }^{1,2}$ \\ Rehena Sultana ${ }^{3}$ \\ Tze-Ern Chua iD ${ }^{4,5}$ \\ Helen Yu Chen ${ }^{4,5}$ \\ Alex Tiong Heng Sia ${ }^{1,2}$ \\ Ban Leong Sng ${ }^{1,2}$ \\ 'Department of Women's Anaesthesia, \\ KK Women's and Children's Hospital, \\ Singapore; ${ }^{2}$ Anaesthesiology and \\ Perioperative Sciences Academic Clinical \\ Program, Duke-NUS Medical School, \\ Singapore; ${ }^{3}$ Centre for Quantitative \\ Medicine, Duke-NUS Medical School, \\ Singapore; ${ }^{4}$ Department of Psychological \\ Medicine, KK Women's and Children's \\ Hospital, Singapore; ${ }^{5}$ Paediatrics \\ Academic Clinical Program, Duke-NUS \\ Medical School, Singapore
}

Purpose: Postnatal depression (PND) is associated with maternal morbidity and socioeconomic burden. Recent studies have shown an association between pain catastrophizing, increased labor pain, and subsequent adverse postnatal adjustment; however, little is known on its role in PND development. We aimed to investigate the association between pain catastrophizing and probable PND.

Methods: Parturients planning to undergo epidural labor analgesia were recruited. Predelivery questionnaires, including the Pain Catastrophizing Scale (PCS) and Edinburgh Postnatal Depression Scale (EPDS), were administered during early labor. A phone survey at 5- 9 weeks postdelivery was conducted to determine postdelivery EPDS and Spielberger's State-Trait-Anxiety Inventory scores. The primary outcome was a binary variable of postdelivery EPDS with cutoff of $\geq 10$, whereas the secondary outcome was a continuous variable on increases in EPDS score.

Results: Probable PND (EPDS $\geq 10$ ) occurred in 10.5\% (95\% CI 8.0\%-13.5\%, 55 of 525) of women who underwent epidural labor analgesia. We found that high pain catastrophizing (PCS $\geq 25$ ) was associated with increased postdelivery EPDS scores (adjusted $\beta$ estimate $0.36,95 \%$ CI $0.15-0.57$; $p=0.0008$ ), but did not meet significance for increased risk of probable PND $(p=0.1770)$. Additionally, presence of breakthrough pain during epidural analgesia (adjusted $\beta$ estimate $0.24,95 \%$ CI $0.02-0.46 ; p=0.0306$ ) and lower BMI at term (adjusted $\beta$ estimate $-0.04,95 \%$ CI -0.07 to $-0.01 ; p=0.0055$ ) were associated with increased postdelivery EPDS scores.

Conclusion: No significant association was found between high pain catastrophizing and probable PND; however, high predelivery pain catastrophizing, presence of breakthrough pain during epidural analgesia, and lower BMI at term were associated with increased postdelivery EPDS scores. Further research will be needed to validate this association in the context of the risk of PND development.

Keywords: pain catastrophizing, breakthrough pain, epidural analgesia, postnatal depressive states

\section{Introduction}

Postnatal depression (PND) is a significant maternal mental health problem and associated with long term psychological and socioeconomic impact. The incidence of PND varies among studies depending on the classification, reporting, and study population. A meta-analysis of 59 studies on 12,810 subjects revealed that $10 \%$ $15 \%$ of parturients may experience PND within the first year after giving birth. ${ }^{1}$ In Singapore, the incidence of PND is about $8 \%-13 \% .^{2,3}$ PND is associated with
Correspondence: Ban Leong Sng

Tel +656394 I08I

Fax +65 6291266I

Email sng.ban.leong@singhealth.com.sg

Neuropsychiatric Disease and Treatment 2020:16 1853-1862 
adverse maternal and neonatal consequences, and in rare cases even suicide or infanticide. ${ }^{4}$

Gaudet et al found that parturients with greater perinatal pain had more frequent PND symptoms. ${ }^{5}$ Similarly, Eisenach et al found that the severity of acute postnatal pain, regardless of the mode of delivery and degree of physical trauma, is an important contributor to chronic pain and PND after childbirth. ${ }^{6}$ Psychological and biological factors may also contribute to PND, including pain severity, negative experiences during childbirth, underlying psychological vulnerabilities, analgesic techniques, and genetic susceptibility ${ }^{7}$ however, their exact link with PND remains unclear.

Pain catastrophizing is an exaggerated negative mental set brought to bear during actual or anticipated painful experience, and comprises rumination, magnification, and helplessness. ${ }^{8}$ Ferber et al reported that postnatal catastrophizers had poorer postnatal physical recovery, higher incidence of maternity blues (transient change of mood in mothers during the first few days after delivery, characterized by weeping, mild depressive mood, anxiety, and lability of mood), ${ }^{9}$ and poorer postnatal social functioning, all of which were positively correlated with the degree of catastrophizing, rather than the actual intensity of labor pain. ${ }^{10}$ It has been shown that pain catastrophizing is positively associated with the fear of being overwhelmed by labor pain and the fear of pain during the insertion of an epidural needle during epidural labor analgesia. ${ }^{11}$ Various studies have demonstrated that a Pain Catastrophizing Scale (PCS) score of 30 and more is associated with clinically relevant pain catastrophizing in the general adult population. ${ }^{12,13}$ However, this cutoff is further lowered to $20-25$ in parturients. ${ }^{10,14}$ Flink et al used 20 as a cutoff in an obstetric population, which reflected the median score of the whole group. ${ }^{14}$ Ferber et al has independently found that the whole-group median was 20-25 (25 when measured intrapartum and 20 when measured 2 days postpartum). ${ }^{10}$ Since PCS in our study was measured intrapartum, we found 25 to be the most suitable cutoff.

In this study, participants were grouped according to their PCS scores, defined as low (PCS $<25$ ) and high (PCS $\geq 25$ ) pain catastrophizers. We investigated whether high predelivery pain catastrophizing was associated with the binary variable of postdelivery Edinburgh Postnatal Depression Scale (EPDS) scores (a cutoff of $\geq 10$ ) as the primary outcome. We also investigated predelivery factors associated with increased changes in postdelivery EPDS scores as the secondary outcome, and also determined predelivery factors that were associated with high predelivery pain-catastrophizing status.

\section{Methods}

\section{Patient Recruitment}

This prospective cohort study was a secondary analysis of data collected from a clinical trial investigating the efficacy of different epidural delivery-maintenance regimens. The study was conducted between January 2015 and March 2019 in KK Women's and Children's Hospital, Singapore on parturients who received epidural analgesia for labor. The study protocol was developed according to the Strengthening the Reporting of Observational studies in Epidemiology (STROBE) guidelines on reporting cohort studies. The study was reviewed and approved by the SingHealth Centralized Institutional Review Board, Singapore (SingHealth CIRB ref 2014/670/D or 2018/ 3128), and registered on ClinicalTrials.gov (NCT02278601) on October 26, 2014.

The study included nulliparous parturients aged 21-50 years, 36 gestational weeks or more, with a singleton fetus, American Society of Anesthesiologists' physical status I and II, and in early labor (cervical dilation $<5 \mathrm{~cm}$ ) who had requested epidural labor analgesia. Parturients with multiple pregnancies, noncephalic fetal presentation, obstetric complications (eg, preeclampsia, premature rupture of membranes), contraindications to neuraxial blockade, had received parenteral opioids within 2 hours prior to initiation of epidural analgesia, or had suspected inadvertent dural puncture during initiation of epidural analgesia were excluded.

All epidurals utilized the B Braun Espocan set with a combined spinal-epidural technique using a conventional single interspace needle-through-needle approach. The spinal component was ropivacaine $2 \mathrm{mg}$ and fentanyl $15 \mathrm{mcg}$ and the epidural infusion solution $0.1 \%$ ropivacaine with $2 \mu \mathrm{g} / \mathrm{mL}$ of fentanyl. Almost all cases ( $>99 \%$ ) were done in the sitting position and utilized a midline approach. The clinical trial involved patients who were placed on patientcontrolled epidural analgesia regimens with patient bolus of $5 \mathrm{~mL}$ per bolus. Once the patient had received epidural labor analgesia and was comfortable, predelivery questionnaires were administered: the PCS, a validated self-reported questionnaire to evaluate the negative thought processes that one may have upon exposure to actual or anticipated pain or painful experiences; the EPDS, a ten-item self-reported questionnaire used as a screening tool for antenatal and PND, scored from 0 to 30 , with $\geq 10$ used to indicate clinically 
significant depressive symptoms ${ }^{15,16}$ (in our study, this was defined as probable PND and would thus encompass the range of PND states); ${ }^{17}$ Cohen's Perceived Stress Scale (PSS), a ten-item validated psychometric instrument to quantify the perception of stress; and Spielberger's State-TraitAnxiety Inventory (STAI), a 40-item self-report tool that assesses transient anxiety (state) at the moment of scoring, the dispositional anxiety (trait), and anxiety in general. Parturients' demographic, obstetric, and epidural analgesia data from medical records were also collected in this study. After patients had delivered, they were interviewed by the anesthetic team for assessment of overall satisfaction with epidural analgesia, as per routine clinical practice. A 20-min ute phone survey was conducted at 5-9 weeks postdelivery to obtain postdelivery EPDS and STAI scores.

\section{Statistical Analysis}

Cohorts were defined as low and high pain-catastrophizing groups with PCF cutoffs of $<25$ and $\geq 25$, respectively. The primary outcome was defined as EPDS score $\geq 10$ at the postdelivery phone survey, and was treated as binary data with status "yes" or "no". The primary objective was to evaluate whether high pain catastrophizing was associated with the binary variable of the EPDS score. No samplesize calculation was performed, as this was a secondary analysis of the primary trial.

Demographic, clinical, and anesthetic characteristics were summarized based on the group. Categorical data are summarized as frequency (proportion) and continuous data summarized as means \pm SD) or medians (ranges), whichever was appropriate. To find the association between pain catastrophizing and PND states, we used logistic regression. Quantitative associations between PND states and pain catastrophizing are reported as ORs with 95\% CIs. We investigated the predelivery factors associated with postdelivery EPDS score at 5-9 weeks on thepostdelivery phone survey as continuous data (secondary outcome). We fitted a generalized linear model (GLM) for normal distribution, with an identity-link function for postdelivery EPDS scores. Univariate and multivariate GLMs for postdelivery EPDS scores were fitted to find associations between postdelivery EPDS scores and other potential confounding factors. Variables with $p<0.05$ in the univariate GLM were selected for the multivariate model. We used backward variable selection to decide on the final multivariate model. Quantitative associations from the GLM are reported as $\beta$ estimates with $95 \%$ CIs. Significance was set at $p<0.05$, and all tests were two-tailed. SAS version 9.4 software (SAS Institute, Cary, $\mathrm{NC}, \mathrm{USA}$ ) was used for all analyses.

\section{Results}

We recruited 805 parturients in this study: $463(57.5 \%)$ in the low and $342(42.5 \%)$ in the high pain-catastrophizing groups (Figure 1). Among these, 152 (32.8\% among low pain-catastrophizing group) and 135 (39.5\% among high pain-catastrophizing group) were lost to follow-up. A total of 518 participants completed the 5- to 9-weeks postdelivery surveys. In this study, the overall prevalence of probable PND at 5-9 weeks postdelivery was found to be $10.5 \%$ (95\% CI 8.0\%-13.5\%), with 9.0\% (28 of 311) and $12.7 \%$ (26 of 204) in the low and high paincatastrophizing groups respectively. We found no significant association between high pain catastrophizing and the binary variable of EPDS score at cutoff of $\geq 10$ $(p=0.1770)$.

Comparson of the low and high pain-catastrophizing groups (Tables 1 and 2) showed that there was no significant difference in demographic or obstetric characteristics, except age $(30.0 \pm 4.1$ years vs $29.3 \pm 4.5$ years, $p=0.0361)$ and duration of third stage of labor $(4.8 \pm 5.7$ minutes vs $6.6 \pm 16.4$ minutes, $p=0.0440$ ). In addition, those in the high paincatastrophizing group were more likely to be Indians ( $p=0.0490$ ) or Malays ( $p=0.0004)$. We examined the association of epidural labor analgesia-related factors stratified by predelivery pain-catastrophizing total scores (Table 3). Compared to low pain catastrophizing group, high pain catastrophizing was associated with increased preblock pain scores on a numeric rating scale of $0-10(6.7 \pm 2.6$ vs 6.2 $\pm 2.7, p=0.0094)$, more anesthetists required for epidural analgesia $(p=0.0082)$, and presence of breakthrough pain (98 [28.7\%] vs 95 [20.5\%], $p=0.0075$ ). No significant differences were found between the high and low paincatastrophizing groups for analgesia prior to receiving epidural analgesia ( $p=0.0709)$, number of attempts at epidural insertion ( $1.2 \pm 0.5$ vs $1.2 \pm 0.5, p=0.7366)$, time taken for epidural insertion $(8.1 \pm 5.7$ minutes vs $7.4 \pm 4.8$ minutes, $p=0.0638)$, or post-block pain score of $0-10(0.2 \pm 0.8$ vs 0.2 $\pm 0.8, p=0.7556)$. There were no epidural failures reported, as the trial recruited only those with successful epidural placement.

We also investigated pain- and psychology-related measures in both low and high pain-catastrophizing groups (predelivery [EPDS, PCS, STAI, and PSS] and 5- 9 weeks postdelivery [EPDS and STAI]; Table 4]). In the high pain-catastrophizing group, all subcomponents 




Figure I Study flowchart. Predelivery assessments State-Trait-Anxiety Inventory (STAI). Patients' demographic, obstetric, and epidural analgesia data from medical records were also collected in this study. At 5-9 weeks postdelivery, EPDS and STAI scores were collected via phone survey.

of predelivery PCS (rumination, magnification, helplessness) were significantly greater than in the low pain-catastrophizing group $(p<0.0001)$. Similarly, during the predelivery survey, the high pain-catastrophizing group had greater PSS $(17.0 \pm 5.5$ vs 14.3 \pm 5.4 , $p<0.0001)$, STAI $(78.7 \pm 18.0$ vs $69.6 \pm 15.4, p<0.0001)$, and EPDS $(8.6 \pm 4.7$ vs $6.5 \pm 3.9, p<0.0001)$ scores compared to the low pain-catastrophizing group. At 5-9 weeks postdelivery, STAI and EPDS scores had decreased from the predelivery period among the whole study population. Notably, the decrease in STAI (state anxiety $-p=0.3498$, trait anxiety $-p=0.3889$, overall anxiety $-p=0.3053)$ and $\operatorname{EPDS}(p=0.8436)$ scores were greater among women in the high paincatastrophizing group than the low pain-catastrophizing group; however, the differences were not statistically significant. Instead, the high pain-catastrophizing group still had higher scores on postdelivery anxiety (31.4 \pm 9.6 vs $28.7 \pm 8.4, p=0.0009)$, trait anxiety $(34.2 \pm 10.1$ vs 30.4 $\pm 8.8, p<0.0001)$, overall anxiety $(65.6 \pm 19.1$ vs 59.2 $\pm 16.2, p<0.0001)$, and postdelivery depressive symptoms $(4.0 \pm 4.5$ vs $2.9 \pm 3.9, p=0.0046)$.
Table 5 shows the univariate and multivariate GLM analysis investigating factors associated with postdelivery EPDS scores. Variables with $p<0.05$ in the univariate GLM model are shown in the tables. The univariate GLM model showed that parturients with lower BMI at term, increased number of attempts at epidural insertion, longer time taken for epidural insertion, presence of breakthrough pain, increased predelivery PCS total score, and all subcomponent (rumination, magnification, helplessness), predelivery PSS, predelivery STAI (state, trait, total), and predelivery EPDS scores were all associated with higher risk of increased postdelivery EPDS score. Specifically, the high pain-catastrophizing group was associated with increased postdelivery EPDS scores (unadjusted $\beta$ estimate 0.32 , 95\% CI $0.11-0.53$; $p=0.0033$ ). Upon GLM multivariate logistic regression (Table 5), three factors were identified as independent associated factors for increased postdelivery EPDS score: increased predelivery pain catastrophizing (adjusted $\beta$ estimate 0.36 , 95\% CI $0.15-0.57 ; p=0.0008)$, presence of breakthrough pain during epidural analgesia (adjusted $\beta$ estimate 0.24 , 95\% CI 0.02-0.46; $p=0.0306$ ), and lower 
Table I Demographic Characteristics (Stratification Based on Predelivery PCS Scores)

\begin{tabular}{|c|c|c|c|}
\hline & $\begin{array}{l}\text { Low Pain- } \\
\text { Catastrophizing } \\
\text { Group } \\
(\text { PCS }<25) \text {, } \\
n=463\end{array}$ & $\begin{array}{l}\text { High Pain- } \\
\text { Catastrophizing } \\
\text { Group } \\
(\text { PCS } \geq 25) \text {, } \\
\text { n=342 }\end{array}$ & $p$-value \\
\hline Age (years) & $30.0 \pm 4.1$ & $29.3 \pm 4.5$ & 0.0361 \\
\hline Race & & & 0.0040 \\
\hline Chinese & $275(59.4)$ & $189(55.3)$ & - \\
\hline Malay & $61(13.2)$ & $32(9.4)$ & - \\
\hline Indian & $60(13.0)$ & $76(22.2)$ & - \\
\hline Other & $67(14.5)$ & 45 (13.2) & - \\
\hline Weight (kg) & $69.9 \pm 11.3$ & $69.7 \pm 11.1$ & 0.8288 \\
\hline Height $(\mathrm{cm})$ & $1.6 \pm 0.1$ & $1.6 \pm 0.1$ & 0.1541 \\
\hline $\begin{array}{l}\text { BMI at } \\
\text { term }\left(\mathbf{k g} / \mathrm{m}^{2}\right)\end{array}$ & $27.3 \pm 4.4$ & $27.7 \pm 4.8$ & 0.3505 \\
\hline $\begin{array}{l}\text { ASA physical } \\
\text { status }\end{array}$ & & & 0.0928 \\
\hline I & $398(86.0)$ & $279(81.6)$ & - \\
\hline II & $65(14.0)$ & $63(18.4)$ & - \\
\hline Gravida & $1.2 \pm 0.5$ & $1.2 \pm 0.6$ & 0.8827 \\
\hline $\begin{array}{l}\text { Gestational } \\
\text { age (weeks) }\end{array}$ & $37.8 \pm 1.7$ & $37.6 \pm 2.4$ & 0.3212 \\
\hline
\end{tabular}

Notes: Values expressed as means \pm SD or $n(\%)$; $p$-values generated via $\chi^{2}$ tests for categorical variables or $t$-tests for continuous variables.

Abbreviations: ASA, American Society of Anesthesiologists; PCS, Pain Catastrophizing Scale.

BMI at term (adjusted $\beta$ estimate $-0.04,95 \% \mathrm{CI}-0.07$ to $-0.01 ; p=0.0055)$.

\section{Discussion}

In this Asian-population cohort study, high predelivery pain-catastrophizing (PCS $\geq 25$ ) was not associated with probable PND, as defined by EPDS $\geq 10$, at 5-9 weeks postdelivery. However, increased predelivery pain catastrophizing (PCS $\geq 25$ ), presence of breakthrough pain during epidural analgesia, and a lower BMI at term were associated with increased postdelivery EPDS scores.

The effect of pain catastrophizing has been investigated in the setting of labor, where increased PCS scores were positively associated with fear of overwhelming labor pain and pain avoidance during delivery. ${ }^{11}$ Flink et al further classified parturients as catastrophizers and noncatastrophizers based on a PCS cutoff of 20, and showed that the former group had greater anticipated and actual pain and poorer physical recovery; however, they did not collect data on psychological factors, eg, anxiety and depressive symptoms before or after delivery. ${ }^{14}$ Similar studies also demonstrated a positive correlation between high pain catastrophizing and pain in the perinatal period; ${ }^{18,19}$ however, thus far only one study has reported the effect of high pain catastrophizing on maternity blues at 2 days after delivery. ${ }^{10}$ Interestingly, one study on 114 parturients revealed that high pain catastrophizing was not associated with usage of epidural analgesia, probably due to equivocal perception toward epidural analgesia in catastrophizers. ${ }^{11}$ Our findings of high predelivery pain catastrophizing being associated with increased postdelivery EPDS scores suggest that negative expectations of labor pain are associated with greater depressive symptoms. In several pain conditions (eg, chronic low-back pain, neck pain, or fibromyalgia), the use of cognitive behavioral therapy, acceptance and commitment therapy, or multimodal treatment comprising cognitive behavioral therapy and physical therapy were found to provide modest benefits to patients with high pain catastrophizing. ${ }^{20}$ Future research is warranted to develop treatment for high pain-catastrophizing parturients, especially after delivery.

Predelivery PCS scores were collected upon successful initiation of epidural analgesia, and no statistical differences were found between the high and low paincatastrophizing groups on rate of epidural failure, breakthrough pain, or repeat procedures. It was however noted that in the high pain-catastrophizing group, a second anesthetist might be called upon to assist more frequently, but the number of attempts and total time taken for insertion did not vary between high and low paincatastrophizing groups. Scores on postdelivery questionnaires were taken after the epidural analgesia-delivery process, presence of breakthrough pain, or epidural failures, but these was analyzed as per an intention-to-treat analysis, and hence the groups were analyzed on predelivery PCS scores only.

Breakthrough pain refers to pain occurring after the institution of epidural analgesia that requires additional unscheduled intervention, eg, local anesthetic solution or opioid topups. $^{21}$ Several studies have reported that the requirement for repeated supplemental medication is associated with longer duration of analgesia, posterior fetal presentation at birth, and cesarean or instrumental delivery. $^{22,23}$ Likewise, Hess et al demonstrated that nulliparity, heavier fetal weight, epidural catheter placement during early cervical dilation, and use of epidural analgesia, as opposed to combined spinal-epidural analgesia, were independent predictors for breakthrough pain during labor. ${ }^{24}$ To our knowledge, this is the first study reporting 
Table 2 Obstetric Characteristics (Stratification Based on Predelivery PCS Scores)

\begin{tabular}{|c|c|c|c|}
\hline & $\begin{array}{l}\text { Low Pain-Catastrophizing Group } \\
\text { (PCS <25), } \\
n=463\end{array}$ & $\begin{array}{l}\text { High Pain-Catastrophizing Group } \\
\text { (PCS } \geq 25) \\
\text { n=342 }\end{array}$ & $p$-value \\
\hline Mode of labor onset & & & 0.2025 \\
\hline Spontaneous & $241(52.1)$ & $158(46.2)$ & - \\
\hline Prostin & $|4|(30.5)$ & $123(36.0)$ & - \\
\hline Artificial rupture of membranes & $81(17.5)$ & $61(17.8)$ & - \\
\hline Duration of second stage of labor ( $\mathrm{min}$ ) & $58.6 \pm 59.2$ & $65.4 \pm 65.1$ & 0.1315 \\
\hline Duration of third stage of labor (min) & $4.8 \pm 5.7$ & $6.6 \pm 16.4$ & 0.0440 \\
\hline Birth weight (g) & $3120.3 \pm 366.3$ & $3105.5 \pm 397.5$ & 0.5880 \\
\hline Birth length $(\mathrm{cm})$ & $49.2 \pm 2.0$ & $49.0 \pm 1.9$ & 0.1632 \\
\hline Head circumference $(\mathrm{cm})$ & $33.6 \pm 1.3$ & $33.5 \pm 1.2$ & 0.2331 \\
\hline Sex & & & 0.8338 \\
\hline Male & $247(53.4)$ & $185(54.1)$ & - \\
\hline Female & $216(46.7)$ & $157(45.9)$ & - \\
\hline Apgar score (I min) & $9(2$ to 9$)$ & $9(1$ to 9$)$ & 0.0921 \\
\hline Apgar score (5 min) & 9 (3 to 9) & $9(1$ to 9$)$ & 0.3287 \\
\hline Placenta weight $(\mathrm{g})$ & $604.7 \pm 126.7$ & $598.4 \pm 115.7$ & 0.4681 \\
\hline Mode of delivery & & & 0.3221 \\
\hline Normal vaginal & $254(54.9)$ & $204(59.7)$ & - \\
\hline Instrumental (vacuum/forceps) & $73(15.8)$ & $53(15.5)$ & - \\
\hline Cesarean & $136(29.4)$ & $85(24.9)$ & - \\
\hline \multicolumn{4}{|l|}{ Neonate resuscitation } \\
\hline No & $153(33.1)$ & $113(33.0)$ & 0.9989 \\
\hline Suction & $302(65.2)$ & $218(63.7)$ & 0.6634 \\
\hline Bag and mask & $2(0.4)$ & $6(1.8)$ & 0.0615 \\
\hline Intubation & $\mathrm{I}(0.2)$ & $3(0.9)$ & 0.1872 \\
\hline Patient satisfaction $(0-100)^{a}$ & $90.5 \pm 9.3$ & $89.1 \pm 11.4$ & $0.07 I I$ \\
\hline
\end{tabular}

Notes: Values expressed as means $\pm \mathrm{SD}$, medians (range), or $\mathrm{n}(\%)$; $p$-values generated via $\chi^{2}$ tests for categorical variables or $t$-tests for continuous variables. ${ }^{a}$ For this variable, there were $28(6.1 \%)$ missing data from the low pain-catastrophizing group and $23(6.7 \%)$ missing data from the high pain-catastrophizing group.

Abbreviation: PCS, Pain Catastrophizing Scale.

that presence of breakthrough pain is associated with increased postdelivery EPDS scores. Eisenach et al demonstrated that those who experienced severe acute pain within 36 hours postdelivery had triple the risk of developing PND of those who had mild postdelivery pain. ${ }^{6}$ Ding et al showed that the use of epidural analgesia was associated with a decreased risk of PND compared with no epidural analgesia; however, the association of labor-pain intensity and PND intensity andPND states was not assessed. ${ }^{25}$ It has been shown that term pregnancy confers increased pain tolerance, especially during the active phase of labor. ${ }^{26,27}$ In this study, we found no significant association between preblock pain scores and postdelivery EPDS scores. We postulate that high pain-catastrophizing patients could be more likely to exhibit significant discomfort at the point of initiation of epidural analgesia, and the primary anesthetist would have a lower threshold to seek help if any difficulty were faced. However, we found there was no increased difficulty in this group, as evidenced by the similar time to perform epidural analgesia compared with the low pain-catastrophizing group. It is also possible that patients in the high pain-catastrophizing group would have a lower threshold to seek help for pain, hence the higher occurrence of breakthrough pain.

The association between BMI and general depression has been investigated, ${ }^{28,29}$ but there have been mixed results on the relationship between prepregnancy BMI and postnatal mood symptoms. ${ }^{30,31,32}$ For instance, Silverman et al reported that a U-shaped association was found between first-trimester BMI extremes (BMI $<18.5$ or BMI $>35$ ) and PND. ${ }^{30}$ However, that study did not determine a causal link, and this observation may be attributed to other factors 
Table 3 Pain Characteristics (Stratification Based on Predelivery PCS Scores)

\begin{tabular}{|c|c|c|c|}
\hline & $\begin{array}{l}\text { Low Pain Catastrophizing } \\
\text { Group } \\
(\text { PCS <25), } \\
n=463\end{array}$ & $\begin{array}{l}\text { High Pain Catastrophizing } \\
\text { Group } \\
(\text { PCS } \geq 25) \\
\text { n=342 }\end{array}$ & p-value \\
\hline Analgesia prior to receiving epidural analgesia & & & 0.0709 \\
\hline Nil & 197 (46.7) & $122(39.1)$ & - \\
\hline Entonox & $206(48.8)$ & $179(57.8)$ & - \\
\hline Pethidine & $19(4.5)$ & II (3.5) & - \\
\hline Preblock pain score $(0-10)^{a}$ & $6.2 \pm 2.7$ & $6.7 \pm 2.6$ & 0.0094 \\
\hline Number of anesthetists & & & 0.0082 \\
\hline 1 & $440(95.0)$ & $309(90.3)$ & - \\
\hline 2 & $21(4.5)$ & $33(9.7)$ & - \\
\hline 3 & $2(0.4)$ & $0(0.0)$ & - \\
\hline Number of attempts at epidural insertion & $1.2 \pm 0.5$ & $1.2 \pm 0.5$ & 0.7366 \\
\hline $\begin{array}{l}\text { Total time taken for epidural insertion } \\
\text { (mins) }{ }^{b}\end{array}$ & $7.4 \pm 4.8$ & $8.1 \pm 5.7$ & 0.0638 \\
\hline Postblock pain score $(0-10)$ & $0.2 \pm 0.8$ & $0.2 \pm 0.8$ & 0.7556 \\
\hline Breakthrough pain & $95(20.5)$ & $98(28.7)$ & 0.0075 \\
\hline Required repeat procedure & $5(1.1)$ & $4(1.2)$ & 1 \\
\hline
\end{tabular}

Notes: Values expressed as means \pm SD or $n(\%)$; $p$-values generated via $\chi^{2}$ test for categorical variables or $t$-tests for continuous variables. ${ }^{a}$ For this variable, there were 53 (II.5\%) missing data from the low pain-catastrophizing group and 29 (8.5\%) missing data from the high pain-catastrophizing group. ${ }^{b}$ For this variable, there were 15 (3.2\%) missing data from the low pain catastrophizing group and nine $(2.6 \%)$ missing data from the high pain-catastrophizing group.

Abbreviation: PCS, Pain Catastrophizing Scale.

associated with obesity, such as family history, medical history, and environmental effects. Within the healthy nulliparous parturients in our study, we found that lower BMI at term was associated with greater postdelivery EPDS scores, which could be reflective of the likelihood of the depressive state having been present antenatally. ${ }^{33}$ Avalos et al showed that persistent poor intake, a classical feature of antenatal depression, can result in low BMI, which in turn can affect fetal development. ${ }^{34}$ Related evidence from a large Singaporean perinatal cohort on adverse neonatal outcomes suggested a relationship with reduced birth weight and antenatal depression. ${ }^{35}$

Table 4 Psychological Characteristics (Stratification Based on Predelivery PCS Scores)

\begin{tabular}{|c|c|c|c|}
\hline Characteristics & $\begin{array}{l}\text { Low Pain-Catastrophizing Group } \\
\text { (PCS <25), } \\
n=463\end{array}$ & $\begin{array}{l}\text { High Pain-Catastrophizing Group } \\
\text { (PCS } \geq 25 \text { ), } \\
\text { n=342 }\end{array}$ & $p$-value \\
\hline \multicolumn{4}{|l|}{ Predelivery } \\
\hline PSS $(0-40)$ & $14.3 \pm 5.4$ & $17.0 \pm 5.5$ & $<0.0001$ \\
\hline STAI — state anxiety $(20-80)$ & $35.1 \pm 9.1$ & $39.0 \pm 10.3$ & $<0.0001$ \\
\hline STAI — trait anxiety $(20-80)$ & $34.5 \pm 7.7$ & $39.6 \pm 9.2$ & $<0.0001$ \\
\hline STAI - total score $(40-160)$ & $69.6 \pm 15.4$ & $78.7 \pm 18.0$ & $<0.0001$ \\
\hline EPDS $(0-30)$ & $6.5 \pm 3.9$ & $8.6 \pm 4.7$ & $<0.0001$ \\
\hline \multicolumn{4}{|l|}{ Postdelivery (5-9 weeks) } \\
\hline STAI - state anxiety score ${ }^{a}$ & $28.7 \pm 8.4$ & $31.4 \pm 9.6$ & 0.0009 \\
\hline STAI - trait anxiety score ${ }^{a}$ & $30.4 \pm 8.8$ & $34.2 \pm 10.1$ & $<0.0001$ \\
\hline STAI - total score ${ }^{a}$ & $59.2 \pm 16.2$ & $65.6 \pm 19.1$ & $<0.0001$ \\
\hline EPDS $(0-30)^{\mathrm{b}}$ & $2.9 \pm 3.9$ & $4.0 \pm 4.5$ & 0.0046 \\
\hline
\end{tabular}

Notes: Values expressed as means \pm SD; $p$-values generated via $t$-tests. ${ }^{a}$ For these variables, there were 153 (33\%) missing data from the low pain-catastrophizing group and $136(39.8 \%)$ missing data from the high pain-catastrophizing group due to loss of follow-up. bor this variable, there were $152(32.8 \%)$ missing data from the low paincatastrophizing group and 138 (40.4\%) missing data from the high pain-catastrophizing group due to loss of follow-up.

Abbreviations: EPDS, Edinburgh Postnatal Depression Scale; PCS, Pain Catastrophizing Scale; PSS, Perceived Stress Scale; STAI, State-Trait-Anxiety Inventory. 
Table 5 Univariate and Multivariate Generalized Linear Model to Find Factors Associated with EPDS Scores

\begin{tabular}{|c|c|c|c|c|}
\hline & Unadjusted $\beta$ Estimate $(95 \% \mathrm{Cl})$ & p-value & Adjusted $\beta$ Estimate $(95 \% \mathrm{Cl})$ & $p$-value \\
\hline BMl at term $\left(\mathrm{kg} / \mathrm{m}^{2}\right)$ & $-0.04(-0.07$ to -0$)$ & 0.0277 & $-0.04(-0.07,-0.01)$ & 0.0055 \\
\hline Number of attempts for epidural insertion & $0.21(0.07-0.36)$ & 0.0036 & - & - \\
\hline Total time taken for epidural insertion & $0.02(0-0.03)$ & 0.0141 & - & - \\
\hline Breakthrough pain (yes) & $0.25(0.03-0.48)$ & 0.0273 & $0.24(0.02,0.46)$ & 0.0306 \\
\hline PCS - rumination (predelivery) & $0.03(0.01-0.06)$ & 0.0117 & - & - \\
\hline PCS - magnification (predelivery) & $0.07(0.04-0.11)$ & $<0.0001$ & - & - \\
\hline PCS - helplessness (predelivery) & $0.03(0.01-0.04)$ & 0.0015 & - & - \\
\hline PCS - total score (predelivery) & $0.02(0.01-0.02)$ & 0.0005 & - & - \\
\hline PCS - total score $\geq 25$ (predelivery) & $0.32(0.11-0.53)$ & 0.0033 & $0.36(0.15,0.57)$ & 0.0008 \\
\hline PSS (predelivery) & $0.06(0.04-0.08)$ & $<0.0001$ & - & - \\
\hline STAI — state anxiety (predelivery) & $0.03(0.02-0.04)$ & $<0.0001$ & - & - \\
\hline STAI — trait anxiety (predelivery) & $0.04(0.03-0.05)$ & $<0.0001$ & - & - \\
\hline STAI — total score (predelivery) & $0.02(0.01-0.02)$ & $<0.0001$ & - & - \\
\hline EPDS (predelivery) & $0.09(0.07-0.11)$ & $<0.0001$ & - & - \\
\hline
\end{tabular}

Note: Parameters with $p<0.05$ in the univariate generalized linear model were included in this table.

Abbreviations: EPDS, Edinburgh Postnatal Depression Scale; PCS, Pain Catastrophizing Scale; PSS, Perceived Stress Scale; STAI, State-Trait-Anxiety Inventory.

Our univariate analysis showed that both age and duration of the third stage of labor were significantly associated with increased probability of PND (EPDS $\geq 10$ ); however, such significance was not demonstrated on multivariate analysis, implying that these factors might be potential confounders for our suggested model. Those in the high pain-catastrophizing were more likely to be Indians or Malays. Previous research has shown that Indian and Malay patients who underwent Cesarean delivery reported higher pain and used more morphine than Chinese; however, this is unknown in patients undergoing vaginal delivery. ${ }^{36}$ It is possible that differences in culture and perceptions of the birth process may contribute to the findings, though future research is warranted.

There are some limitations to this study. Firstly, the cutoff for PCS scores varies by ethnicity or sociocultural and linguistic factors, ${ }^{10}$ and hence different PCS cutoffs should be explored and validated in other populations. Additionally, it has been reported that Asians may have different perceptions and attitudes toward pain compared with individuals from other regions and ethnic groups ${ }^{37}$ Secondly, this study included only healthy nulliparous parturients. It is possible that nulliparous parturients may have different psychological profiles, perspectives, and expectations about the delivery process and postdelivery management from multiparous parturients. This in turn could possibly affect the degree of pain catastrophizing, depressive symptoms, and ability to cope after delivery. Thirdly, we recruited only parturients who requested epidural analgesia, and outcomes may differ from parturients who did not receive epidural analgesia. Parturients who did not opt for epidural analgesia may have different demographic backgrounds in terms of sociocultural beliefs, pain tolerance, and expectations, all of which could contribute to mental health status, and these effects were not investigated. The inclusion criteria of the primary trial on recruiting those having nulliparous early labor and with epidural inserted may have limited the applicability of the findings to a wider laboring population. However, this design also allowed a more homogeneous population, so as to investigate the true effects of pain catastrophizing and other risk factors. Furthermore, as this study was a secondary analysis of a clinical trial, a priori sample-size calculation was not performed. Finally, we acknowledge that changes in EPDS scores may not have direct clinical significance with regard to PND. Affonso et al used effect-size estimates to determine that EPDS of 4 points or more was considered a "large" change, whereas 2-3 points was a "medium" change. ${ }^{38}$ Further mathematical calculation on the reliablechange index to measure clinical significance showed that a 4-point change was needed to be $95 \%$ confident that a real change had occurred in the individual. ${ }^{39}$ In our study, a statistically significant 2-point difference in predelivery PCS scores between the study groups allowed the interpretation of when patients "on average" had lower depressive symptoms in the low pain-catastrophizing group than the high pain-catastrophizing group; however, this may not allow further interpretation on clinical significance of how many women showed lower depressive symptoms in each group. Future research is needed to verify the clinical significance of our findings. 


\section{Conclusion}

In this study, we showed that high pain catastrophizing was not itself associated with probable PND 5-9 weeks after delivery. However, high predelivery pain catastrophizing, lower BMI at term, and the presence of breakthrough pain during epidural analgesia were associated with increased EPDS scores 5-9 weeks after delivery. This suggests that pain severity and pain vulnerability have an important association with increased depressive symptoms and may contribute to PND states. Prospective studies to validate our findings are needed to confirm the impact of the proposed association model. Future research will also evaluate the usefulness of this model to be implemented for risk stratification and early interventional therapy to reduce PND and PND states.

\section{Abbreviations}

ASA, American Society of Anesthesiologists; EPDS, Edinburgh Postnatal Depression Scale; GLM, generalized linear model; HPA, hypothalamic-pituitary-adrenal; NRS, numeric rating scale; PCS, Pain Catastrophizing Scale; PND, postnatal depression; PSS, Perceived Stress Scale; RCI, Reliable-Change Index; ROC, receiver-operating characteristic; STAI, State-Trait-Anxiety Inventory; STROBE, Strengthening Reporting of Observational Studies in Epidemiology.

\section{Data-Sharing Statement}

The data sets generated and analyzed in this work are available for anyone who wishes to access the data by contacting the corresponding author.

\section{Ethics Approval and Informed Consent}

The study was approved by the SingHealth Centralized Institutional Review Board, Singapore (SingHealth CIRB reference 2014/670/D or 2018/3128) and registered on ClinicalTrials.gov (NCT02278601) on October 26,2014 . The authors declare that all recruited patients provided informed consent and that this work was conducted in accordance with the Declaration of Helsinki.

\section{Consent for Publication}

All patients provided informed consent on the use of their deidentified data for publication purpose.

\section{Acknowledgments}

We would like to thank Ms Agnes Teo (Senior Clinical Research Coordinator), Yvonne Yong (Senior Clinical Research Coordinator), and Denise Anne (Clinical Research Coordinator) for their administrative support in this work.

\section{Author Contributions}

Yanzhi Zeng and Chin Wen Tan contributed equally to manuscript preparation. All authors contributed to the study design, data analysis and discussion, drafting and/ or revising the manuscript. All authors approved the final version of the manuscript and agree to be accountable for all aspects of this work.

\section{Funding}

This work was supported by funding from a National Medical Research Council Clinical Trials Grant Investigator-Initiated Trials (CTG13feb013). The aforementioned sponsor was not involved in the study activities.

\section{Disclosure}

All authors report no conflicts of interest in this work.

\section{References}

1. O'hara MW, Swain AM. Rates and risk of postpartum depression-a meta-analysis. Int Rev Psychiatry. 1996;8(1):37-54. doi:10.3109/ 09540269609037816

2. Suhitharan T, Pham TPT, Chen H, et al. Investigating analgesic and psychological factors associated with risk of postpartum depression development: a case-control study. Neuropsychiatr Dis Treat. 2016;12:1333.

3. Helen C. Addressing maternal mental health needs in Singapore. Psychiatr Serv. 2011;62(1):102. doi:10.1176/ps.62.1.pss6201 0102

4. Esscher A, Essen B, Innala E, et al. Suicides during pregnancy and 1 year postpartum in Sweden, 1980-2007. Br J Psychiatry. 2016;208 (5):462-469. doi:10.1192/bjp.bp.114.161711

5. Gaudet C, Wen SW, Walker MC. Chronic perinatal pain as a risk factor for postpartum depression symptoms in Canadian women. Can J Public Health. 2013;104(5):e375-e387. doi:10.17269/cjph.104. 4029

6. Eisenach JC, Pan PH, Smiley R, Lavand'homme P, Landau R, Houle TT. Severity of acute pain after childbirth, but not type of delivery, predicts persistent pain and postpartum depression. Pain. 2008;140(1):87-94. doi:10.1016/j.pain.2008.07.011

7. Halbreich U. Postpartum Disorders: Multiple Interacting Underlying Mechanisms and Risk Factors. 2005.

8. Sullivan MJ, Bishop SR, Pivik J. The pain catastrophizing scale: development and validation. Psychol Assess. 1995;7(4):524. doi:10. 1037/1040-3590.7.4.524

9. Kennerley H, Gath D. Maternity blues: I. Detection and measurement by questionnaire. Br J Psychiatry. 1989;155(3):356-362. doi:10.11 92/bjp.155.3.356

10. Ferber SG, Granot M, Zimmer EZ. Catastrophizing labor pain compromises later maternity adjustments. Am J Obstet Gynecol. 2005;192 (3):826-831. doi:10.1016/j.ajog.2004.10.589 
11. Van den Bussche E, Crombez G, Eccleston C, Sullivan MJ. Why women prefer epidural analgesia during childbirth: the role of beliefs about epidural analgesia and pain catastrophizing. Eur J Pain. 2007;11(3):275-282. doi:10.1016/j.ejpain.2006.03.002

12. Osman A, Barrios FX, Gutierrez PM, Kopper BA, Merrifield T, Grittmann L. The pain catastrophizing scale: further psychometric evaluation with adult samples. J Behav Med. 2000;23(4):351-365. doi:10.1023/A:1005548801037

13. Kortlever JT, Janssen SJ, van Berckel MM, Ring D, Vranceanu AM. What is the most useful questionnaire for measurement of coping strategies in response to nociception? Clin Orthop Relat Res. 2015;473(11):3511-3518. doi:10.1007/s11999-015-4419-2

14. Flink IK, Mroczek MZ, Sullivan MJ, Linton SJ. Pain in childbirth and postpartum recovery-the role of catastrophizing. Eur J Pain. 2009;13(3):312-316. doi:10.1016/j.ejpain.2008.04.010

15. Wisner KL, Parry BL, Piontek CM. Postpartum depression. N Engl J Med. 2002;347(3):194-199. doi:10.1056/NEJMcp011542

16. Cox JL, Holden JM, Sagovsky R. Detection of postnatal depression: development of the 10-item Edinburgh postnatal depression scale. $\mathrm{Br}$ J Psychiatry. 1987;150(6):782-786. doi:10.1192/bjp.150.6.782

17. Chen H, Wang J, Ch'ng YC, Mingoo R, Lee T, Ong J. Identifying mothers with postpartum depression early: integrating perinatal mental health care into the obstetric setting. ISRN Obstet Gynecol. 2011;2011:1-7. doi:10.5402/2011/309189

18. Olsson C, Buer N, Holm K, Nilsson-Wikmar L. Lumbopelvic pain associated with catastrophizing and fear-avoidance beliefs in early pregnancy. Acta Obstet Gynecol Scand. 2009;88(4):378-385. doi:10.1080/00016340902763210

19. Soares ADS, de Menezes Couceiro TC, Lima LC, Flores FLL, Alcoforado EMB, de Oliveira Couceiro Filho R. Association of pain catastrophizing with the incidence and severity of acute and persistent perineal pain after natural childbirth: longitudinal cohort study. Braz J Anesthesiol. 2013;63(4):317-321. doi:10.1016/j. bjane.2012.12.001

20. Schütze R, Rees C, Smith A, Slater H, Campbell JM, O'Sullivan P. How can we best reduce pain catastrophizing in adults with chronic noncancer pain? A systematic review and meta-analysis. J Pain. 2018;19(3):233-256. doi:10.1016/j.jpain.2017.09.010

21. Goodman P, Mackey MC, Tavakoli AS. Factors related to childbirth satisfaction. $J$ Adv Nurs. 2004;46(2):212-219. doi:10.1111/j.13652648.2003.02981.x

22. Le Coq G, Ducot B, Benhamou D. Risk factors of inadequate pain relief during epidural analgesia for labour and delivery. Can $J$ Anaesth. 1998;45(8):719. doi:10.1007/BF03012140

23. Hess PE, Pratt SD, Soni AK, Sarna MC, Oriol NE. An association between severe labor pain and cesarean delivery. Anesth Analg. 2000;90(4):881-886. doi:10.1213/00000539-200004000-00020

24. Hess PE, Pratt SD, Lucas TP, et al. Predictors of breakthrough pain during labor epidural analgesia. Anesth Analg. 2001;93(2):414-418.

25. Ding T, Wang D-X, Qu Y, Chen Q, Zhu S-N. Epidural labor analgesia is associated with a decreased risk of postpartum depression: a prospective cohort study. Anesth Analg. 2014;119(2):383-392. doi:10.1213/ANE.0000000000000107
26. Carvalho B, Angst MS, Fuller AJ, Lin E, Mathusamy AD, Riley ET. Experimental heat pain for detecting pregnancy-induced analgesia in humans. Anesth Analg. 2006;103(5):1283-1287. doi:10.1213/01. ane.0000239224.48719.28

27. Ohel I, Walfisch A, Shitenberg D, Sheiner E, Hallak M. A rise in pain threshold during labor: a prospective clinical trial. Pain. 2007;132: S104-S108. doi:10.1016/j.pain.2007.05.007

28. Luppino FS, de Wit LM, Bouvy PF, et al. Overweight, obesity, and depression: a systematic review and meta-analysis of longitudinal studies. Arch Gen Psychiatry. 2010;67(3):220-229. doi:10.1001/ archgenpsychiatry.2010.2

29. De Wit LM, Van Straten A, Van Herten M, Penninx BW, Cuijpers P. Depression and body mass index, a u-shaped association. $B M C$ Public Health. 2009;9(1):14. doi:10.1186/1471-2458-9-14

30. Silverman ME, Smith L, Lichtenstein P, Reichenberg A, Sandin S. The association between body mass index and postpartum depression: a population-based study. J Affect Disord. 2018;240:193-198. doi:10.1016/j.jad.2018.07.063

31. LaCoursiere DY, Baksh L, Bloebaum L, Varner MW. Maternal body mass index and self-reported postpartum depressive symptoms. Matern Child Health J. 2006;10(4):385-390. doi:10.1007/s10995-006-0075-1

32. Krause KM, Østbye T, Swamy GK. Occurrence and correlates of postpartum depression in overweight and obese women: results from the active mothers postpartum (AMP) study. Matern Child Health J. 2009;13(6):832. doi:10.1007/s10995-008-0418-1

33. Evans J, Heron J, Lewis G, Araya R, Wolke D. Negative self-schemas and the onset of depression in women: longitudinal study. $\mathrm{Br}$ J Psychiatry. 2005;186(4):302-307. doi:10.1192/bjp.186.4.302

34. Avalos LA, Caan B, Nance N, et al. Prenatal depression and diet quality during pregnancy. J Acad Nutr Diet. 2020;120(6):972-984. doi:10.1016/j.jand.2019.12.011

35. Lim HA, Chua T-E, Malhotra R, et al. Identifying trajectories of antenatal depression in women and their associations with gestational age and neonatal anthropometry: a prospective cohort study. Gen Hosp Psychiatry. 2019;61:26-33. doi:10.1016/j.genhosppsych.2019.09.001

36. Tan E-C, Lim Y, Teo Y-Y, Goh R, Law H-Y, Sia AT. Ethnic differences in pain perception and patient-controlled analgesia usage for postoperative pain. J Pain. 2008;9(9):849-855. doi:10.1016/j.jpain. 2008.04.004

37. Watson PJ, Latif RK, Rowbotham DJ. Ethnic differences in thermal pain responses: a comparison of South Asian and White British healthy males. Pain. 2005;118(1-2):194-200. doi:10.1016/j.pain.20 05.08.010

38. Affonso DD, De AK, Horowitz JA, Mayberry LJ. An international study exploring levels of postpartum depressive symptomatology. J Psychosom Res. 2000;49(3):207-216. doi:10.1016/S0022-399 9(00)00176-8

39. Matthey S. Calculating clinically significant change in postnatal depression studies using the Edinburgh postnatal depression scale. J Affect Disord. 2004;78(3):269-272. doi:10.1016/S0165-0327(02) 00313-0
Neuropsychiatric Disease and Treatment

\section{Publish your work in this journal}

Neuropsychiatric Disease and Treatment is an international, peerreviewed journal of clinical therapeutics and pharmacology focusing on concise rapid reporting of clinical or pre-clinical studies on a range of neuropsychiatric and neurological disorders. This journal is indexed on PubMed Central, the 'PsycINFO' database and CAS, and is the official journal of The International Neuropsychiatric Association (INA). The manuscript management system is completely online and includes a very quick and fair peer-review system, which is all easy to use. Visit http://www.dovepress.com/testimonials.php to read real quotes from published authors. 